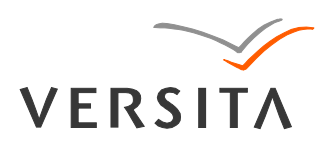

GEOCHRONOMETRIA 41(1) 2014: 1-14

DOI 10.2478/s13386-013-0143-4

Available online at

www.springerlink.com

\title{
MULTI-METHOD LUMINESCENCE INVESTIGATIONS ON QUARTZ GRAINS OF DIFFERENT SIZES EXTRACTED FROM A LOESS SECTION IN SOUTHEAST ROMANIA INTERBEDDING THE CAMPANIAN IGNIMBRITE ASH LAYER
}

\author{
VALENTINA ANECHITEI-DEACU ${ }^{1,2}$, ALIDA TIMAR-GABOR ${ }^{1,2}$, KATHRYN E. FITZSIMMONS $^{3}$, \\ DANIEL VERES ${ }^{1,2,4}$ and ULRICH HAMBACH ${ }^{5}$ \\ ${ }^{I}$ Faculty of Environmental Science and Engineering, Babeş-Bolyai University, Fântânele 30, 400294 Cluj Napoca, Romania \\ ${ }^{2}$ Interdisciplinary Research Institute on Bio-Nano-Science of Babeş-Bolyai University, \\ Treboniu Laurean 42, 400271 Cluj-Napoca, Romania \\ ${ }^{3}$ Department of Human Evolution, Max Planck Institute for Evolutionary Antropology, Deutscher Platz 6, D-04103, Leipzig, Germany \\ ${ }^{4}$ Institute of Speology, Romanian Academy, 400006, Cluj Napoca, Romania \\ ${ }^{5}$ Chair of Geomorphology, Laboratory for Palaeo-and Enviro-Magnetism, University of Bayreuth, Germany
}

Received 20 July 2013

Accepted 21 October 2013

\begin{abstract}
In this study we present luminescence investigations of four samples of loess bracketing the Campanian Ignimbrite/Y5 tephra at the Rasova-Valea cu Pietre site, on the eastern bank of the Danube River, southeastern Romania. Investigations involved SAR-OSL dating on aliquots of fine $(4-11 \mu \mathrm{m})$ and medium-grained $(63-90 \mu \mathrm{m})$ quartz, as well as single grain analyses on $125-180 \mu \mathrm{m}$ quartz. Luminescence dating results coupled with glass-shard chemical fingerprinting assign the depositional age and origin of the ash layer to that of the Campanian Ignimbrite/Y5 tephra, dated elsewhere using ${ }^{40} \mathrm{Ar} /{ }^{39} \mathrm{Ar}$ to $39.28 \pm 0.11 \mathrm{ka}$. Fine-grained $(4-11 \mu \mathrm{m})$ quartz SAR-OSL analyses yielded ages of $44.4 \pm 4.5 \mathrm{ka}$ below the ash, and $41.4 \pm 4.2 \mathrm{ka}$ above the ash layer. Single grain analysis on coarse-grained quartz, however, demonstrates that coarse material from these samples exhibits low sensitivity and responds poorly to internal checks of the SAR protocol in comparison with the finer sediment. This observation highlights the need for more extensive investigations into the luminescence properties of quartz as well as into the origin of quartz contributions from different primary sources in the Lower Danube loess steppe.
\end{abstract}

Keywords: quartz, SAR-OSL, single grain OSL, loess, Campanian Ignimbrite/Y5.

\section{INTRODUCTION}

A number of volcanic ash occurrences within Pleistocene loess and fluvial deposits in the Lower Danube region of Romania have recently been assigned to the Campanian Ignimbrite/Y5 (hereafter CI) tephra by glass

Corresponding author: A. Timar-Gabor

e-mail: alida.timar@ubbcluj.ro chemical fingerprinting and OSL dating of adjacent material (Constantin et al., 2012; Veres et al., 2013; Fitzsimmons et al., 2013). The CI tephra, originating in the Phlegrean fields of southern Italy and dated by ${ }^{40} \mathrm{Ar} /{ }^{39} \mathrm{Ar}$ to $39.28 \pm 0.11 \mathrm{ka}$ (De Vivo et al., 2001) has been widely identified in lacustrine, marine, loess and cave sediments, extending across the eastern Mediterranean and eastern Europe to north Africa and the Russian Plain (Thunnel et 
al., 1978; Ton-That et al., 2001; Pyle et al., 2006; Anikovich et al., 2007). The CI eruption occurred during a significant time period coinciding with the extremely cold climate phase Heinrich Event 4, the arrival of anatomically modern humans into Europe and the disappearance of the Neanderthals from the continent (Lowe et al., 2012; Fitzsimmons et al., 2013, Fedele et al., 2003). Consequently, new CI occurrences in the poorly studied loess steppe of Eastern Europe could strengthen its impact as an important marker horizon at sub-continental scale (Veres et al., 2013).

Despite the fact that loess is generally believed to be an ideal material for luminescence dating, from our previous studies on Mircea Vodă (Timar-Gabor et al., 2011), Mostiștea (Timar-Gabor et al., 2012) and Costinești (Constantin et al., in press) loess-paleosol sections, the fine grain $(4-11 \mu \mathrm{m})$ quartz OSL chronology yielded ages significantly younger than the coarser grains (63-90 $\mu \mathrm{m})$. The offsets between the two datasets range from 15 to $35 \%$ for samples collected from the loess interval L1 (ie., post-Eemian), while the differences in L2 (pre-Eemian) amount to as much as $52 \%$. It appears that the age discrepancy resides in the different equivalent doses, the fine-grained equivalent doses being in all cases much lower than the medium-grained quartz equivalent doses, which is in contradiction with the expectations inferred from annual dose considerations. Along with the observed difference in the equivalent doses, the study of Timar-Gabor et al. (2012) has also drawn attention to the different laboratory dose response growth pattern of sandsized $(63-90 \mu \mathrm{m})$ and fine-silt quartz grains $(4-11 \mu \mathrm{m})$. The latter also exhibits much higher saturation characteristics.

Recently, Timar-Gabor and Wintle (2013) presented empirical evidence that for at least high doses the SAR

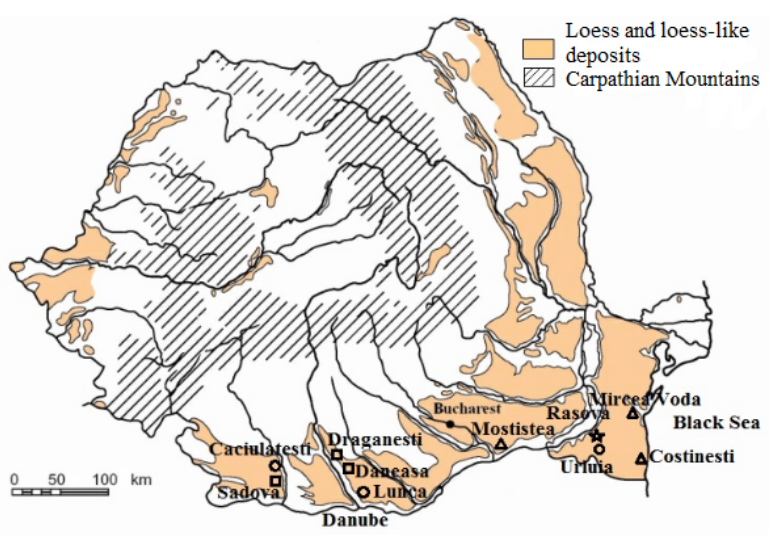

Fig. 1. Map of Romania with the location of the Rasova-Valea cu Pietre site indicated by a star. The profiles previously investigated by luminescence dating are depicted as triangles. Locations where tephra occurrences have been identified and assigned to the Campanian Ignimbrite/Y-5 tephra by geochemical analyses are represented by squares. Locations investigated using both luminescence dating and geochemistry are represented by circles. dose response curves obtained in the laboratory do not reflect the growth of the signals in nature, both for fine $(4-11 \mu \mathrm{m})$ and medium $(63-90 \mu \mathrm{m})$ grained quartz extracted from Costineşti loess section. This finding casts doubt on the validity of the higher equivalent doses obtained by applying the SAR protocol, such as $>200-300$ Gy for fine grains and 100-200 Gy in the case of medium-grained quartz.

Here we present luminescence chronological investigations on four samples of loess bracketing a recently identified CI tephra exposure on the eastern bank of the Danube River at Rasova-Valea cu Pietre, southeastern Romania (Fig. 1). We undertook SAR-OSL dating on aliquots of fine $(4-11 \mu \mathrm{m})$ and medium $(63-90 \mu \mathrm{m})$ quartz grains, as well as single grain SAR-OSL analyses on $125-180 \mu \mathrm{m}$ quartz with a two-fold aim. On the one hand it was intended to chronologically constrain the deposition time of the ash layer at Valea cu Pietre, in combination with the glass chemical data that suggested a genetic link between this ash layer and the CI tephra. On the other hand, we aimed to use the CI as an independently dated marker horizon with an age of $39.28 \pm 0.11 \mathrm{ka}$ (De Vivo et al., 2001) to gain insights into the cause of the severe age discrepancy between the fine and the medium-grained quartz fractions previously reported at several representative loess-paleosol sections in southern Romania in which the CI tephra has not yet been identified (Fig. 1). The present paper focuses on testing the OSL techniques on loess samples bracketing a well-dated marker horizon in order to further investigate the luminescence properties of Romanian loess at various locations and sedimentary settings.

\section{STUDY SITE}

The stratigraphic profile at Valea $\mathrm{cu}$ Pietre $\left(44^{\circ} 15.255^{\prime}\right.$ N; $27^{\circ} 57.088^{\prime}$ E; 28 m a.s.l; Fig. 1$)$, is located near the village of Rasova in southern Dobrogea, in a region known for thick alluvial-aeolian Quaternary deposits (Munteanu et al., 2008). It consists of 7-8 $\mathrm{m}$ of loess overlying Lower Cretaceous carbonates (Pop et al., 1991). No soil development has been identified in the sequence apart from the top $0.5 \mathrm{~m}$ of Holocene soil. The sharp lower contact with the underlying carbonate rocks points to a geological unconformity, a common feature in Dobrogea, reflecting the tectonic activity and long-term geomorphological evolution of the area (see review in Hippolyte, 2002).

A beige-greyish, structureless bed of volcanic ash up to $30 \mathrm{~cm}$ in thickness can be traced laterally along the wall at depths between 5.90 and $6.20 \mathrm{~m}$ from the top of the profile (Fig. 2). Its contact with the underlying loess is very sharp, indicating rapid deposition comparable with that observed at the Urluia sequence nearby (Fitzsimmons et al., 2013). The upper boundary is more gradual, suggesting some degree of mixing between loess and pyroclastic material. 


\section{GLASS GEOCHEMISTRY}

The chemical composition of glass shards $(n=21)$ was determined on epoxy-mounted stubs on a Jeol JXA8200 microprobe using single-grain, wavelengthdispersive electron microprobe analysis (WDS-EPMA) at the Bayerisches GeoInstitut, University of Bayreuth. An accelerating voltage of $15 \mathrm{keV}$ was used with a $6 \mathrm{nA}$ beam current. Peak counting times were $10 \mathrm{~s}$ for $\mathrm{Na}, 30 \mathrm{~s}$ for $\mathrm{Si}, \mathrm{Al}, \mathrm{K}, \mathrm{Ca}, \mathrm{Fe}$ and $\mathrm{Mg}, 40 \mathrm{~s}$ for $\mathrm{Ti}$ and $\mathrm{Mn}$, and $60 \mathrm{~s}$ for P. Precision is estimated at $<1-6 \%(2 \sigma)$ and 10 $25 \%(2 \sigma)$ for major and minor element concentrations respectively. Results of glass shard analyses are summarized in Table 1. Fig. 3 shows a comparison of the geochemical profile of the Rasova-Valea cu Pietre tephra layer with CI ash geochemistry from other proximal and distal deposits.

The provenance of the Valea cu Pietre tephra was fingerprinted based on major oxide concentrations of glass shards that show average $(\mathrm{n}=21) \mathrm{SiO}_{2}$ contents of $60.2 \mathrm{wt} \%$, associated with $7.31 \mathrm{wt} \% \mathrm{~K}_{2} \mathrm{O}, 5.96 \mathrm{wt} \%$ $\mathrm{Na}_{2} \mathrm{O}, 18.46 \mathrm{wt} \% \mathrm{Al}_{2} \mathrm{O}_{3}, 0.39 \mathrm{wt} \% \mathrm{MgO}, 1.82 \mathrm{wt} \% \mathrm{CaO}$ and $2.91 \mathrm{wt} \% \mathrm{FeO}$, respectively (Table 1 ). The silicatotal alkali diagram (Fig. 3) indicates a phonolite/trachyte composition and confirms the close chemical affinity between Valea cu Pietre tephra and other Campanian Ignimbrite/Y-5 (CI) occurrences in the Lower Danube (Fitzsimmons et al., 2013; Veres et al., 2013), vent proximal deposits (Civetta et al., 1997; Signorelli et al., 1999) or even more distal tephra locations (Pyle et al., 2006).

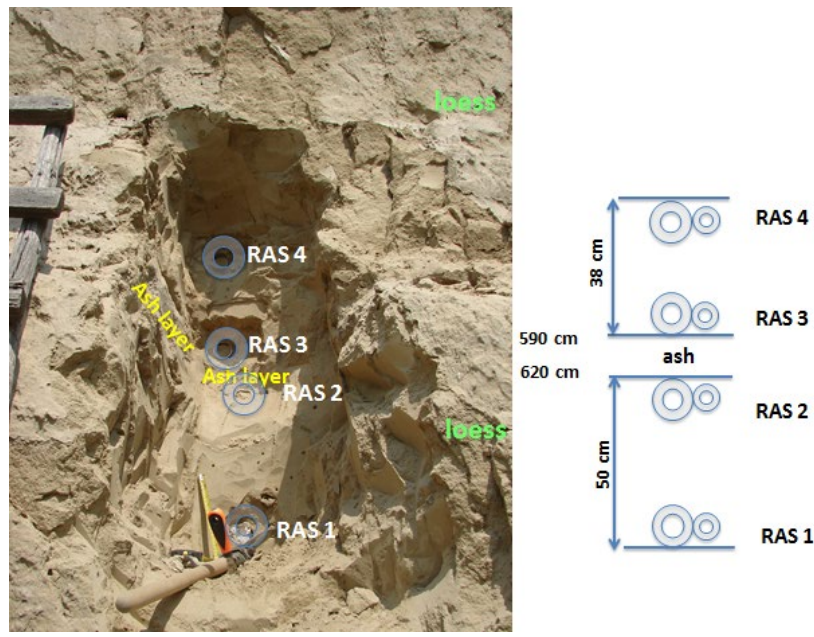

Fig. 2. Photograph and schematic stratigraphic section of the sedimentary profile at Rasova-Valea cu Pietre, including the Campanian Ignimbrite/Y-5 ash occurrence. The stratigraphic position of the luminescence samples is indicated by circles.

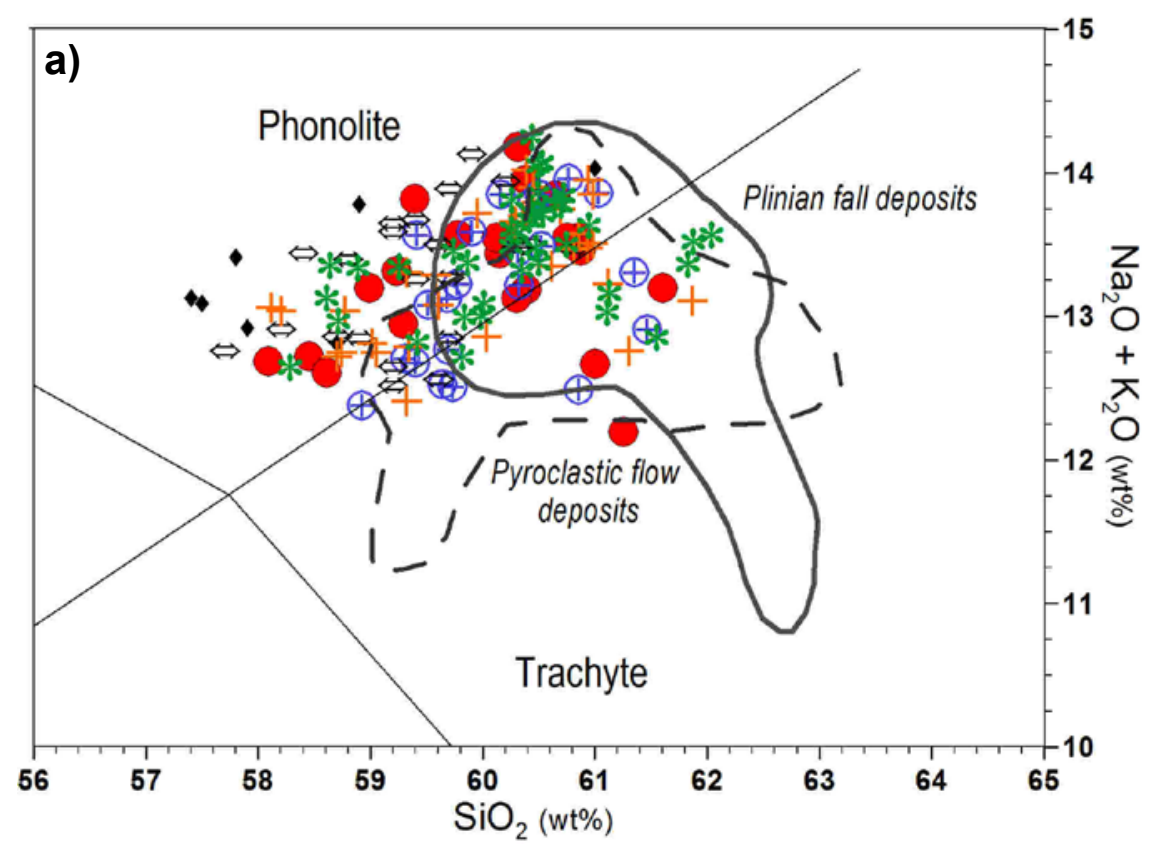

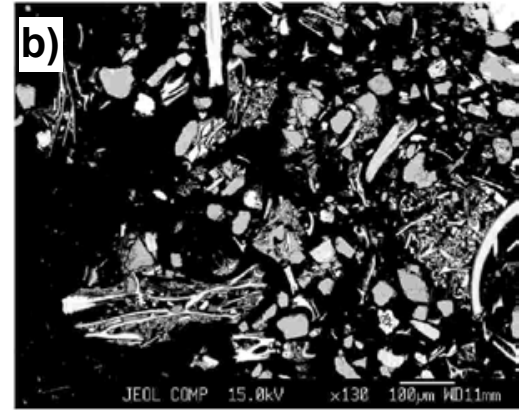

Rasova - Valea cu Pietre

$\oplus$ Urluia

* Caciulatesti

+ Lunca

$\Leftrightarrow$ Rudkino, Russia

$\diamond$ Marine Core TR-172-19-PC

Plinian fall deposits

- _ Pyroclastic flow deposits

Fig. 3. a) Silica-total alkali diagram showing the composition of Rasova-Valea cu Pietre volcanic glass-shards as compared with proximal Campanian Ignimbrite deposits in Italy (Civetta et al., 1997; Signorelli et al., 1999), distal tephra occurrences within Russian loess (Pyle et al., 2006), the fluvial/loess sequence at Caciulatesti in southern Romania (Veres et al., 2013), and the nearby Urluia sequence (Fitzsimmons et al., 2013); b) Scanning electron microscope (SEM) image of the Rasova-Valea cu Pietre tephra. 
Table 1. Chemical results from the WDS-EPMA analyses of glass shards from the Campanian Ignimbrite/Y-5 tephra occurrence at Rasova-Valea cu Pietre. Data are presented as wt\% raw values.

\begin{tabular}{|c|c|c|c|c|c|c|c|c|c|c|c|c|}
\hline Sample & $\mathrm{SiO}_{2}$ & $\mathrm{TiO}_{2}$ & $\mathrm{Al}_{2} \mathrm{O}_{3}$ & $\mathrm{FeO}$ & $\mathrm{MnO}$ & $\mathrm{MgO}$ & $\mathrm{CaO}$ & $\mathrm{Na}_{2} \mathrm{O}$ & $\mathrm{K}_{2} \mathrm{O}$ & $\mathrm{P}_{2} \mathrm{O}_{5}$ & $\mathrm{Cl}^{-}$ & Total \\
\hline \multirow[t]{21}{*}{ RAS-T-2.1 } & 60.39 & 0.358 & 18.59 & 3.01 & 0.245 & 0.339 & 1.7 & 6.47 & 6.72 & 0.054 & 0.790 & 98.6 \\
\hline & 60.85 & 0.458 & 18.85 & 2.95 & 0.237 & 0.310 & 1.64 & 6.4 & 7.15 & 0.044 & 0.702 & 99.5 \\
\hline & 60.87 & 0.359 & 18.59 & 2.83 & 0.236 & 0.325 & 1.77 & 6.47 & 6.99 & 0.083 & 0.781 & 99.3 \\
\hline & 59.78 & 0.442 & 18.59 & 2.86 & 0.237 & 0.345 & 1.79 & 6.33 & 7.24 & 0.022 & 0.770 & 98.4 \\
\hline & 61.25 & 0.354 & 18.54 & 3.22 & 0.094 & 0.717 & 2.48 & 5.06 & 7.14 & 0.091 & 0.320 & 99.2 \\
\hline & 60.31 & 0.431 & 18.62 & 2.96 & 0.217 & 0.299 & 1.68 & 6.29 & 7.89 & 0.049 & 0.721 & 99.4 \\
\hline & 59.29 & 0.414 & 18.26 & 2.9 & 0.212 & 0.315 & 1.74 & 6.12 & 6.83 & 0.056 & 0.764 & 96.9 \\
\hline & 60.38 & 0.437 & 18.6 & 2.82 & 0.243 & 0.365 & 1.67 & 6.12 & 7.83 & 0.017 & 0.731 & 99.2 \\
\hline & 61 & 0.376 & 18.32 & 2.78 & 0.110 & 0.520 & 2.15 & 4.97 & 7.7 & 0.057 & 0.374 & 98.3 \\
\hline & 58.45 & 0.406 & 18.21 & 2.87 & 0.211 & 0.368 & 1.84 & 5.77 & 6.95 & 0.035 & 0.680 & 95.7 \\
\hline & 60.15 & 0.389 & 18.8 & 2.93 & 0.190 & 0.324 & 1.8 & 6.51 & 6.93 & 0.061 & 0.717 & 98.8 \\
\hline & 61.6 & 0.377 & 18.44 & 2.8 & 0.168 & 0.473 & 1.89 & 5.24 & 7.96 & 0.094 & 0.421 & 99.4 \\
\hline & 60.75 & 0.416 & 18.86 & 2.94 & 0.262 & 0.368 & 1.69 & 6.58 & 6.97 & 0.077 & 0.757 & 99.6 \\
\hline & 59.23 & 0.424 & 18.26 & 2.86 & 0.218 & 0.353 & 1.71 & 5.82 & 7.5 & 0.019 & 0.697 & 97.0 \\
\hline & 58.99 & 0.401 & 18.46 & 2.87 & 0.241 & 0.316 & 1.73 & 6.35 & 6.85 & 0.044 & 0.711 & 96.9 \\
\hline & 58.61 & 0.422 & 18.26 & 2.81 & 0.193 & 0.340 & 1.63 & 5.91 & 6.7 & 0.059 & 0.715 & 95.6 \\
\hline & 60.12 & 0.443 & 18.46 & 2.91 & 0.214 & 0.319 & 1.78 & 6.41 & 7.14 & 0.031 & 0.722 & 98.5 \\
\hline & 59.39 & 0.380 & 18.3 & 2.9 & 0.25 & 0.292 & 1.69 & 6.45 & 7.37 & 0.027 & 0.739 & 97.7 \\
\hline & 58.09 & 0.344 & 17.93 & 2.93 & 0.196 & 0.415 & 1.73 & 5.82 & 6.87 & 0.031 & 0.687 & 95.0 \\
\hline & 60.3 & 0.401 & 18.17 & 3.33 & 0.126 & 0.760 & 2.53 & 3.42 & 9.71 & 0.216 & 0.305 & 99.2 \\
\hline & 60.64 & 0.410 & 18.69 & 2.82 & 0.233 & 0.326 & 1.69 & 6.77 & 7.07 & 0.049 & 0.764 & 99.4 \\
\hline Average & 60.02 & 0.40 & 18.59 & 2.91 & 0.206 & 0.390 & 1.82 & 5.96 & 7.31 & 0.058 & 0.660 & 98.2 \\
\hline St. deviation & 0.96 & 0.032 & 0.24 & 0.13 & 0.046 & 0.128 & 0.25 & 0.76 & 0.66 & 0.042 & 0.155 & 1.43 \\
\hline
\end{tabular}

\section{OPTICAL DATING}

\section{Single aliquot measurements}

\section{Samples and analytical facilities}

The extraction of medium $(63-90 \mu \mathrm{m})$ and fine $(4-11 \mu \mathrm{m})$ quartz grains was performed under low intensity red light. Samples were treated to isolate pure quartz of different size fractions $(4-11 \mu \mathrm{m}, 63-90 \mu \mathrm{m}$, and $125-180 \mu \mathrm{m})$ by digestion in dilute hydrochloric acid $(\mathrm{HCl}$; concentration of $10 \%)$ to remove calcium carbonate, and hydrogen peroxide $\left(\mathrm{H}_{2} \mathrm{O}_{2}\right.$; concentration of $10 \%$ followed by $30 \%$ ) to remove organic matter. Fine $(4-11 \mu \mathrm{m})$ grains were extracted using conventional procedures for sample preparation (Lang et al., 1996; Frechen et al., 1996). To isolate the quartz grains from the polymineral fine fraction, samples were digested in $\mathrm{H}_{2} \mathrm{SiF}_{6}$ for 10 days. Separation of medium-grained quartz consisted of sieving, density separation using heavy liquids, and etching with concentrated HF (concentration of $40 \%$ ) for $40 \mathrm{~min}$. The purity of the quartz extracts was certified by the absence of a significant infrared stimulated luminescence (IRSL) response at $60^{\circ} \mathrm{C}$ to a large regenerative $\beta$-dose. An IR depletion test (Duller, 2003) was further employed at the end of each SAR sequence to assess the sensitivity to IR stimulation of each analysed aliquot.

Luminescence investigations were performed using Risø TL/OSL-DA-20 readers equipped with blue
$(470 \pm 30 \mathrm{~nm})$ and infrared $(875 \pm 80 \mathrm{~nm})$ light-emitting diodes. Luminescence signals were detected by EMI 9235QA photomultiplier tubes with coated Hoya U-340 filters. Further details regarding the equipment can be found in Thomsen et al., 2006. Irradiation was carried out using a ${ }^{90} \mathrm{Sr}^{90} \mathrm{Y}$ beta source, calibrated using gamma irradiated calibration quartz produced by the Risø National Laboratory. Dose rates of $0.152 \mathrm{~Gy} / \mathrm{s}, 0.123 \mathrm{~Gy} / \mathrm{s}$ and $0.261 \mathrm{~Gy} / \mathrm{s}$ were obtained for $63-90 \mu \mathrm{m}$ quartz grains deposited on stainless steel, $4-11 \mu \mathrm{m}$ grains mounted on aluminium discs, and $125-180 \mu \mathrm{m}$ single grains mounted on single grain discs, respectively.

\section{Luminescence characteristics}

- Performance of the SAR protocol

The luminescence investigations of the Valea cu Pietre loess samples were performed using the single-aliquot regenerative dose (SAR) protocol (Murray and Wintle, 2000, 2003). Luminescence signals were stimulated with blue diodes for $40 \mathrm{~s}$ at $125^{\circ} \mathrm{C}$. In order to isolate the fast component of the luminescence signal, the net continuous wave OSL (CW-OSL) was evaluated from the initial $0.308 \mathrm{~s}$ of the decay curve, minus a background assessed from the 1.69-2.30 s interval. Unless otherwise mentioned a preheat temperature of $220^{\circ} \mathrm{C}$ for $10 \mathrm{~s}$ and a cutheat to $180^{\circ} \mathrm{C}$ were applied, based on parameters identified as optimal from previous studies on Romanian loess (Timar et al., 2010; Timar-Gabor et al., 2011, 2012; Vasiliniuc et al., 2011; Constantin et al., in press). The 
OSL response to a constant test dose of 16 Gy was used throughout all measurements to correct for sensitivity change. Subsequent to the test dose response measurement, a high-temperature bleach for $40 \mathrm{~s}$ at $280^{\circ} \mathrm{C}$ was performed by stimulation with the blue diodes (Murray and Wintle, 2003).

The OSL signals exhibited a rapid decay during optical stimulation for both fine $(4-11 \mu \mathrm{m})$ and medium $(63-90 \mu \mathrm{m})$ quartz grains. Recycling, IR depletion and recuperation tests were used as indicators of the performance of the SAR protocol applied for the studied samples. Only those aliquots with recycling ratios and IR depletion ratios that did not deviate more than $10 \%$ from unity were accepted for equivalent dose determination. None of the investigated aliquots displayed recuperation values larger than $0.2 \%$ of the natural signal, indicating that the growth curves pass very close to the origin and exhibit negligible thermal transfer of charge during the SAR protocol.

For equivalent dose determination in case of both the fine and medium quartz fractions, sensitivity-corrected growth curves extending up to $\sim 300$ Gy were constructed using 6 regeneration points. The growth of the signal with dose is best described by a sum of two saturating exponential functions. Fig. 4 shows a representative growth curve for an aliquot of medium-grained quartz extracted from sample RAS 1 . The inset presents a typical OSL decay curve for the same quartz fraction of sample RAS 1 .

The reliability of quartz equivalent dose $\left(D_{\mathrm{e}}\right)$ estimation through the SAR protocol employed in this study was investigated using a dose recovery test. The test involved a double bleach for $250 \mathrm{~s}$ at room temperature

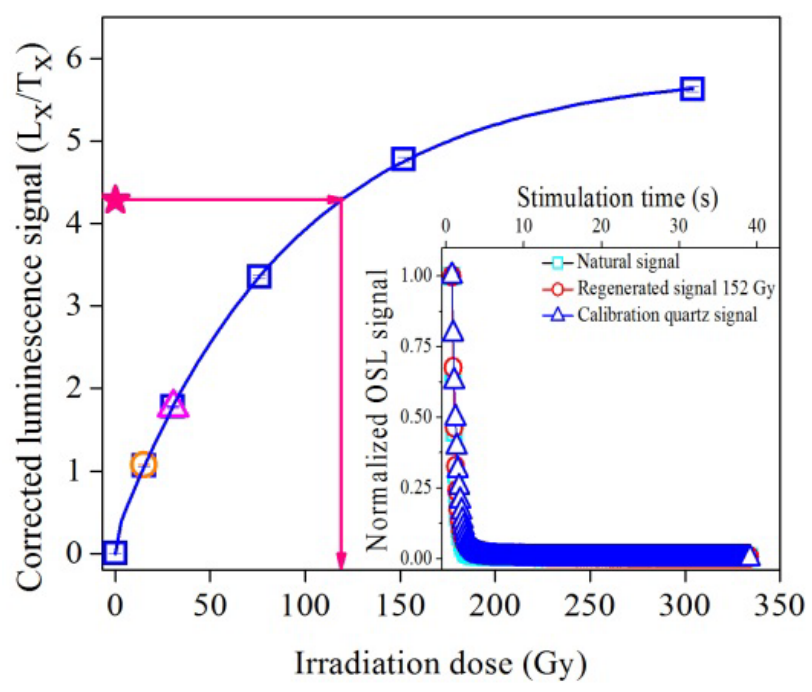

Fig. 4. Representative sensitivity-corrected growth curve from an aliquot of 63-90 $\mu \mathrm{m}$ quartz extracted from sample RAS 1. Open squares illustrate the regenerated doses. The sensitivity-corrected natural signal is shown as a star. The arrows indicate the equivalent dose. Recycling and IR depletion points are represented as an open circle and open triangle, respectively. using blue light emitting diodes, with a $10 \mathrm{ks}$ pause between the stimulations (Murray and Wintle, 2003). Known laboratory doses chosen to be equal to the estimated equivalent doses were then applied to the aliquots which were measured using the SAR protocol. The test was carried out on both the fine $(4-11 \mu \mathrm{m})$ and medium $(63-90 \mu \mathrm{m})$ quartz grains of the investigated samples, using a preheat of $10 \mathrm{~s}$ at $220^{\circ} \mathrm{C}$ in combination with a test dose cut-heat of $180^{\circ} \mathrm{C}$. Unfortunately, due to insufficient material, we were not able to perform the dose recovery test on the medium fraction of sample RAS 4 . The dose recovery data for the preheat at $220^{\circ} \mathrm{C}$ and cut-heat at $180^{\circ} \mathrm{C}$ are displayed in Fig. 5. A deviation of about $10 \%$ above unity of measured to given dose was obtained in all cases, except for the fine fraction $(4-11 \mu \mathrm{m})$ of sample RAS 2 where a very good recovered dose to given dose ratio was observed. The dose recovery test was further applied using a preheat of $260^{\circ} \mathrm{C}$ and cut-heat at $220^{\circ} \mathrm{C}$, in order to investigate the influence of the thermal treatment on the dose recovery ratio. For this thermal treatment, the dose recovery test yielded similar results to the ones previously obtained using lower preheat and cutheat temperatures.

The thermal stability of the signals used for $D_{\mathrm{e}}$ determination was further tested through the preheat plateau test for samples RAS 2 and RAS 3 on both $4-11 \mu \mathrm{m}$ and 63-90 $\mu \mathrm{m}$ quartz grains. The SAR protocol was applied using thermal treatments consisting of a $10 \mathrm{~s}$ preheat at temperatures ranging from $200^{\circ} \mathrm{C}$ to $280^{\circ} \mathrm{C}$ in combination with a test dose cut-heat of $180^{\circ} \mathrm{C}$. No systematic variation in $D_{\mathrm{e}}$ with preheat temperature was observed over this temperature interval. The associated recycling

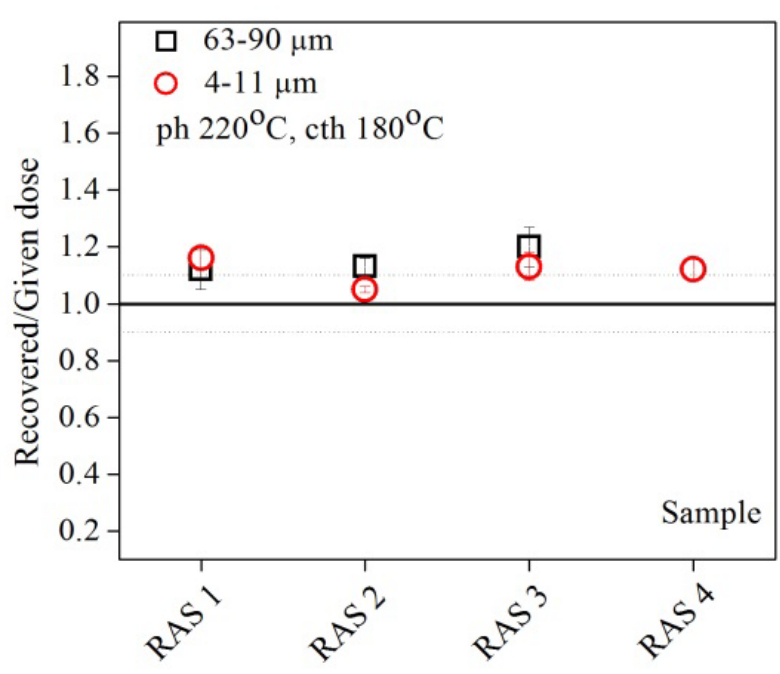

Fig. 5. Dose recovery test results for the 4-11 $\mu \mathrm{m}$ (open circle) and the 63-90 $\mu \mathrm{m}$ (open square) quartz fractions from sample RAS 1. The given doses were chosen to estimate the equivalent doses of the investigated samples. The solid and dashed lines are meant as eye guides and highlight a measured to given dose ratio equal to unity and a $10 \%$ deviation of this ratio from unity, respectively. 
ratios lie close to unity and recuperation does not exceed $0.3 \%$ of the corrected natural OSL signal. Fig. 6 shows the preheat plateau for sample RAS 2. The lack of dependence of $D_{\mathrm{e}}$ on preheat temperature was also observed for sample RAS 3 . These data give us confidence that the OSL signal is not contaminated by thermally unstable components.

- Dose response for very high doses

Dose-response curves up to $\sim 2 \mathrm{kGy}$ were investigated for the fine $(4-11 \mu \mathrm{m})$ and the medium $(63-90 \mu \mathrm{m})$ grained quartz extracted from the sample RAS 4. The sensitivity-corrected growth curves were constructed using 9 regeneration points and a test dose of $16 \mathrm{~Gy}$. Based on the values for the reduced chi square, as well as for the residual sum of the squares (Timar-Gabor et al., 2012), the growth patterns were best fitted by a sum of two saturating exponential functions according to:

$I=I_{0}+A \times\left(1-e^{\left(\frac{-D}{D_{01}}\right)}\right)+B \times\left(1-e^{\left(\frac{-D}{D_{02}}\right)}\right)$

where $I$ - intensity of the OSL signal corresponds to a dose, $D ; I_{0}$ - intercept; $A, B$ - saturation characteristics of the two exponential components; $D_{01}, D_{02}$-doses representing the onset of saturation of each exponential function.

As previously reported in other studies on loess and loess-derived sediments in southern Romania (TimarGabor et al., 2011, 2012; Constantin et al., 2012), a very different pattern of growth was observed for the two quartz grain fractions investigated, with much higher

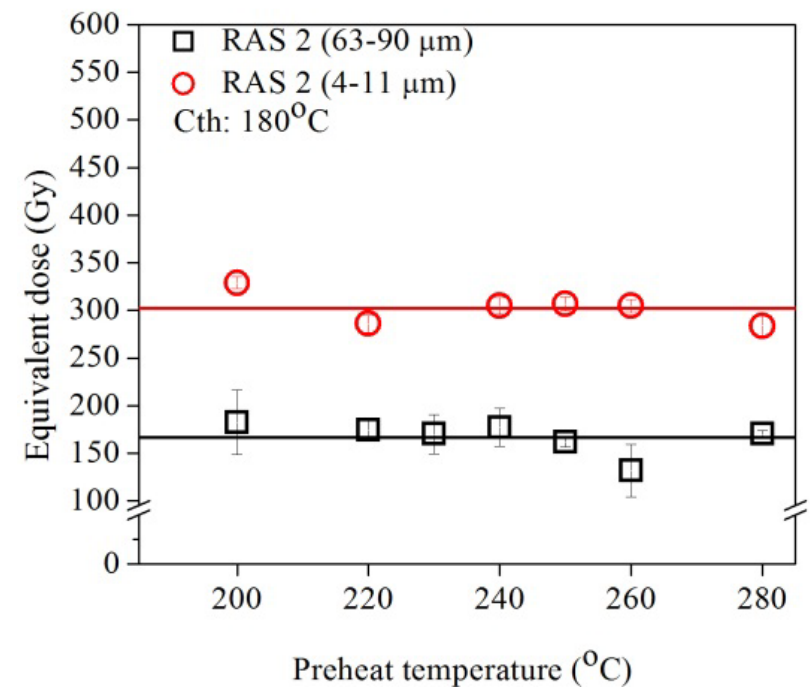

Fig. 6. Dependence of $\mathrm{D}_{\mathrm{e}}$ on preheat temperature for sample RAS 2 on both 4-11 $\mu \mathrm{m}$ (open circles) and 63-90 $\mu \mathrm{m}$ (open squares) quartz grains. Each data point represents the average value $( \pm 1$ standard error) of at least three repeated measurements. saturation doses in the case of the fine quartz (Fig. 7).

For doses exceeding $1 \mathrm{kGy}$, the medium-sized quartz grains reach saturation with an insignificant level of growth, compared to the continuing growth shown by the fine quartz. The values for the characteristic doses $D_{01}$ and $D_{02}$ are $135 \pm 26$ Gy and $1119 \pm 311 \mathrm{~Gy}$, respective$1 y$, for the fine quartz, while for the medium fraction the values are $34 \pm 5 \mathrm{~Gy}$ and $690 \pm 45 \mathrm{~Gy}$, respectively.

- Equivalent doses

The average $D_{\mathrm{e}}$ values ( \pm 1 standard error) are presented in Table 2. For both grain-size fractions extracted from every investigated sample, between 6 and 19 replicate measurements of the $D_{\mathrm{e}}$ were performed. Except for sample RAS 4, higher equivalent doses were obtained using the fine $(4-11 \mu \mathrm{m})$ fraction in comparison to the equivalent doses from the medium $(63-90 \mu \mathrm{m})$ quartz grains. Greater $D_{\mathrm{e}}$ values for the fine quartz grains than for coarser fractions were expected since the dose rate should be higher, due to lack of beta attenuation and contribution of the alpha dose in the former. This behaviour is similar to that reported for a sedimentary section embedding the CI ash layer at the site of Caciulatesti (Constantin et al., 2012) but is in contrast to the previous findings for quartz extracted from loess deposits in southern Romania (Timar-Gabor et al., 2012).

It should be noted however that the samples are relatively young: the values for the equivalent doses range between 136-286 Gy for the fine grains, and 118-175 Gy for the medium grains, respectively (Table 2). Recent investigations at Costinesti (Timar-Gabor and Wintle, 2013) revealed that the laboratory and natural dose re-

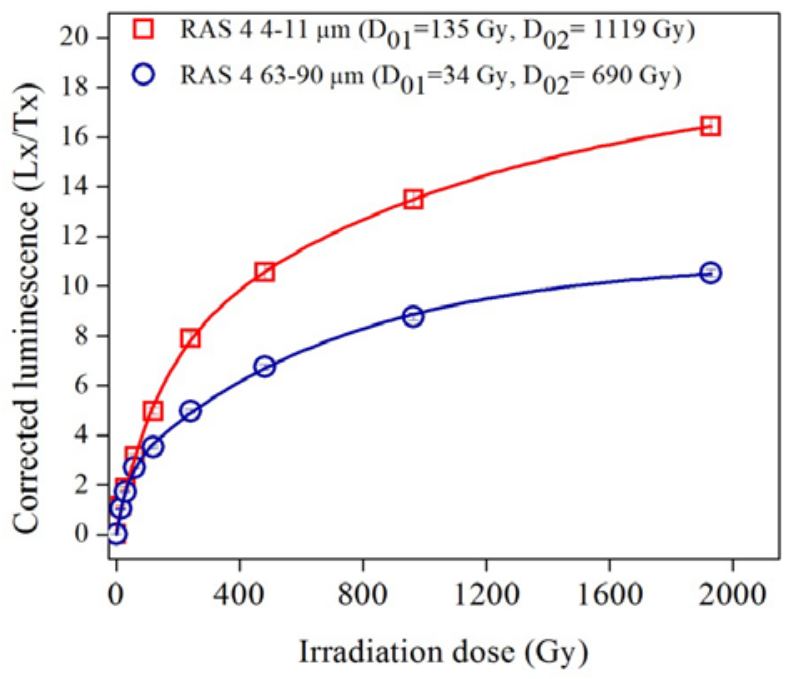

Fig. 7. Comparison between extended dose-response curves constructed for sample RAS 4 using fine $(4-11 \mu \mathrm{m})$ (open squares) and medium-sized (63-90 $\mu \mathrm{m})$ (open circles) quartz grains. Both growth patterns were best described by a double saturating exponential (DSE) function. A test dose of $16 \mathrm{~Gy}$ was used throughout the measurements. 
Table 2. Summary of the luminescence age results. The uncertainties indicated along with the luminescence and dosimetry data are random; the uncertainties mentioned with the optical ages are the overall uncertainties. All uncertainties represent $1 \sigma$.

\begin{tabular}{|c|c|c|c|c|c|c|c|c|c|c|c|c|}
\hline $\begin{array}{l}\text { Sample } \\
\text { code }\end{array}$ & $\begin{array}{l}\text { Depth } \\
(\mathrm{cm})\end{array}$ & $\begin{array}{l}\text { Grain size } \\
(\mu \mathrm{m})\end{array}$ & $n^{1}$ & $\begin{array}{l}\text { Water } \\
\text { content }\end{array}$ & $\begin{array}{c}D_{\mathrm{e}} \\
\text { (Gy) }\end{array}$ & $\begin{array}{c}{ }^{238} \mathrm{U}-226 \mathrm{Ra} \\
(\mathrm{Bq} / \mathrm{kg})\end{array}$ & $\begin{array}{c}{ }^{232} \mathrm{Th} \\
(\mathrm{Bq} / \mathrm{kg})\end{array}$ & $\begin{array}{c}{ }^{40} \mathrm{~K} \\
(\mathrm{~Bq} / \mathrm{kg})\end{array}$ & $\begin{array}{c}\text { Total } \\
\text { random } \\
\text { error }(\%)\end{array}$ & $\begin{array}{c}\text { Total } \\
\text { systematic } \\
\text { error }(\%)\end{array}$ & $\begin{array}{l}\text { Total dose } \\
\text { rate (Gy/ka) }\end{array}$ & $\begin{array}{l}\text { Age } \\
\text { (ka) }\end{array}$ \\
\hline \multirow{2}{*}{ RAS 4} & \multirow{2}{*}{550} & $4-11$ & 8 & \multirow{8}{*}{$5 \%$} & $150 \pm 6$ & \multirow{2}{*}{$40.5 \pm 0.8$} & \multirow{2}{*}{$43.3 \pm 0.1$} & \multirow{2}{*}{$443 \pm 6$} & 3.91 & 9.32 & $3.62 \pm 0.04$ & $41.4 \pm 4.2$ \\
\hline & & $63-90$ & 7 & & $163 \pm 8$ & & & & 4.96 & 6.70 & $2.99 \pm 0.02$ & $54.5 \pm 4.5$ \\
\hline \multirow{2}{*}{ RAS 3} & \multirow[b]{2}{*}{590} & $4-11$ & 11 & & $200 \pm 4$ & \multirow{2}{*}{$59.9 \pm 0.5$} & \multirow{2}{*}{$67.1 \pm 0.1$} & \multirow{2}{*}{$689 \pm 9$} & 2.31 & 9.38 & $5.50 \pm 0.06$ & $36.5 \pm 3.5$ \\
\hline & & $63-90$ & 6 & & $175 \pm 15$ & & & & 5.27 & 6.70 & $4.59 \pm 0.03$ & $38.1 \pm 4.1$ \\
\hline \multirow{2}{*}{ RAS 2} & \multirow{2}{*}{620} & $4-11$ & 19 & & $286 \pm 9$ & \multirow{2}{*}{$39.6 \pm 0.3$} & \multirow{2}{*}{$39.1 \pm 0.3$} & \multirow{2}{*}{$457 \pm 6$} & 3.36 & 9.16 & $3.53 \pm 0.04$ & $81.0 \pm 7.9$ \\
\hline & & $63-90$ & 12 & & $167 \pm 7$ & & & & 4.24 & 6.75 & $2.93 \pm 0.02$ & $57.0 \pm 4.5$ \\
\hline \multirow{2}{*}{ RAS 1} & \multirow{2}{*}{670} & 4-11 & 10 & & $136 \pm 6$ & \multirow{2}{*}{$32.1 \pm 0.5$} & \multirow{2}{*}{$34.0 \pm 0.1$} & \multirow{2}{*}{$410 \pm 6$} & 4.57 & 8.98 & $3.06 \pm 0.04$ & $44.4 \pm 4.5$ \\
\hline & & $63-90$ & 10 & & $118 \pm 5$ & & & & 8.59 & 6.73 & $2.55 \pm 0.02$ & $46.2 \pm 3.7$ \\
\hline
\end{tabular}

${ }^{1} n$ denotes the number of accepted aliquots.

Beta attenuation and etching factor for $63-90 \mu m$ assumed to be $0.94 \pm 0.050$;

Alpha efficiency factor considered was $0.04 \pm 0.02$;

Radionuclide specific activities have been determined through high resolution gamma ray spectrometry.

Cosmic-ray dose rate: RAS $1=0.095 \pm 0.014$ Gy $/ \mathrm{ka}, R A S 2=0.097 \pm 0.015 \mathrm{~Gy} / \mathrm{ka}, R A S 3=0.110 \pm 0.016, R A S 4=0.113 \pm 0.017$.

Water content estimation was based on the difference between the natural "as found" and the oven-dried weight of material from the ends of the tubes, with a relative error of $25 \%$.

The total dose rate consists of the contribution from the alpha, beta and gamma radiations, the contribution from the cosmic rays as well as an internal contribution for the coarse fraction assumed to be $0.01 \mathrm{~Gy} / \mathrm{ka}$.

sponses do not overlap with each other for doses higher than $200 \mathrm{~Gy}$ in the case of fine grains. In the case of medium grains, deviations start to occur at doses as low as $50 \mathrm{~Gy}$, although the precision of the latter value remains under question due to the larger scatter of data (see figure 6 in Timar-Gabor and Wintle, 2013). In the abovementioned study the authors have shown that while the dose response to regenerated signals can be described by a sum of exponentials, the growth of the natural signal is best described by a single saturation exponential model. These findings raise serious doubts as to the reliability of SAR-OSL equivalent doses above certain values obtained for samples where the laboratory dose response cannot be fitted by a single saturation exponential model. In the case of Romanian loess we consider that SAR-OSL equivalent doses higher than $200 \mathrm{~Gy}$ obtained on fine grains are questionable, while in the case of mediumgrained quartz doubts could be raised at even lower values.

\section{Dose rate determination}

Radionuclide specific activities were measured by high-resolution gamma spectrometry and converted to dose rates using the conversion factors tabulated by Adamiec and Aitken (1998). A factor of 0.94 ( \pm 5\% relative uncertainty) was used to correct the external beta dose for the effects of attenuation and etching (Mejdahl, 1979). To allow for the lower efficiency of alpha radiation in inducing luminescence, a value of $0.04 \pm 0.02$ was adopted. A time-averaged water content of $5 \%$ with a relative error of $25 \%$ was considered to account for the effect of moisture. An internal dose rate of $0.010 \pm 0.002 \mathrm{~Gy} / \mathrm{ka}$ was used for the coarser fraction (Vandenberghe et al., 2008). The cosmic ray component of the dose rate was calculated based on equations published in Prescott and Hutton (1994).

\section{Optical ages}

A summary of all the information relevant to the optical age and uncertainty calculation is given in Table 2 . Generally, the systematic uncertainty amounts from 7 to $9 \%($ at $1 \sigma$ ). Our estimates of the uncertainties associated with the time-averaged water content, the $\alpha$-value and beta attenuation factors represent the most considerable sources for the systematic uncertainty. The overall contribution from random sources of uncertainty ranges between $2 \%$ and $\sim 9 \%$ and represents a measure of the internal consistency of the optical ages.

Given the relatively high specific activities for the radionuclides found in sample RAS 3 (see Table 2), we presume that this sample may reflect a mixture of loess and grains/minerals originating from the tephra layer. This could also potentially contaminate the luminescence signal since the high pressure and temperature conditions instrumental in forming the ash raises concerns about the nature of the defects in the crystal lattice. Consequently this may have influenced the intrinsic luminescence properties of the quartz grains originating from the tephra (see review in Preusser et al., 2009). It should be noted that the specific activities measured for ${ }^{238} \mathrm{U}\left({ }^{226} \mathrm{Ra}\right)$ and ${ }^{232} \mathrm{Th}$ for all loess samples analyzed in our previous works are very homogenous, while in the case of sample RAS 3, the obtained values are more than $50 \%$ higher than the average values in the case of both radionuclides. Enrichment in Th concentrations was also observed in samples collected around the ash layer at nearby Urluia sequence (Fitzsimmons et al., 2013; Fitzsimmons and Hambach, in 
press); this is summarised in Table 3. Radionuclide enrichment is further confirmed by unpublished gamma spectrometric analysis $\quad\left({ }^{226} \mathrm{Ra}=81 \pm 2 \mathrm{~Bq} / \mathrm{kg}\right.$, ${ }^{232} \mathrm{Th}=122 \pm 1 \mathrm{~Bq} / \mathrm{kg},{ }^{40} \mathrm{~K}=665 \pm 18 \mathrm{~Bq} / \mathrm{kg}$ ) of a samples from within the ash layer at Caciulatesti previously investigated by Constantin et al. (2012). Such high contents of ${ }^{238} \mathrm{U},{ }^{232} \mathrm{Th}$, and ${ }^{40} \mathrm{~K}$ have also been reported for pyroclastic materials originating from other Southern Italian volcanoes (Civetta et al., 1970; Civetta and Gasparini, 1973; Brai et al., 1995; Bellia et al., 1997, Brai et al., 2002) and are supposed to be directly related to the magmatic mineral assemblages forming these tephra layers.

There is an obvious contrast between the radionuclide activity concentrations in samples RAS 2 and RAS 3, however the equivalent doses have comparable values. The high concentration of radionuclides accounts for the comparably high equivalent doses obtained for sample RAS 3, but this situation does not apply to sample RAS 2. Therefore, the high overestimation of the equivalent doses obtained for sample RAS 2 is counter-intuitive. We interpret these results to reflect intrinsic luminescence properties, however further investigations are necessary. Based on these data, and the relatively large equivalent doses obtained for samples RAS 2 and RAS 3 which suggest that they are unreliable (cf. Timar-Gabor and Wintle, 2013), the optical ages obtained for these two samples will not be considered in further discussions.

Within uncertainties, a very good agreement was found between the optical ages obtained on both quartz grain sizes from RAS 1, whilst for sample RAS 4 an overestimated OSL age was obtained for the mediumgrained $(63-90 \mu \mathrm{m})$ quartz fraction. Optical ages of $44.4 \pm 4.5 \mathrm{ka} \quad(4-11 \mu \mathrm{m}$ quartz $)$ and $46.2 \pm 3.7 \mathrm{ka}$ (63-90 $\mu \mathrm{m}$ quartz) were calculated for the underlying loess layer. For the uppermost loess horizon, $41.4 \pm 4.2 \mathrm{ka}$ $(4-11 \mu \mathrm{m})$ and $54.5 \pm 4.5 \mathrm{ka}(63-90 \mu \mathrm{m})$ values were derived. Only the OSL ages obtained using fine $(4-11 \mu \mathrm{m})$ quartz are consistent with the expected age of
$39.28 \pm 0.11 \mathrm{ka}$ (De Vivo et al., 2001) for the samples associated with CI ash deposition at Valea cu Pietre.

\section{LM-OSL measurements}

Rapid OSL decay was observed in both the natural and regenerated signals of the samples from RasovaValea cu Pietre. Despite this, closer examination (see the inset in Fig. 4) reveals that the OSL decay of the natural and regenerated signals is slightly slower compared to the signal decay of the calibration quartz, which is generally considered as dominated by the fast component. Therefore, linearly-modulated (LM-OSL) measurements were performed to investigate the dominance of the OSL signal by the fast component.

LM-OSL signals were measured at $125^{\circ} \mathrm{C}$ by linearly increasing the stimulation power from 0 to $100 \%$ over $3000 \mathrm{~s}$ after a preheat of the aliquots at $220^{\circ} \mathrm{C}$ for $10 \mathrm{~s}$. These measurements were undertaken for each quartz fraction extracted from the investigated samples.

As displayed in Fig. 8, the LM-OSL signals obtained for the fine fraction of sample RAS 1 show a clear dependency of the relative intensity of the slow component as a function of given dose. Its intensity relative to that of the fast component is higher at lower doses. The same behaviour was exhibited by all grain sizes analysed in all investigated samples. A change in the relative contribution of the fast and the slow components could be due to the saturation of the fast component, the different components having different saturation characteristics. In accordance with previous studies (Bailey, 2000) that suggested that the slow component is described by higher saturation characteristics, the present results are counter-intuitive, as the relative contribution of the slow component to the signal is more important in the case of the low doses compared with higher doses. Further investigation is required to fully understand this behaviour. Our preliminary observations raise questions as to the reliability of using quartz from this particular location for SAR-OSL dating.

\begin{tabular}{lccccc}
\hline Sample code & $\begin{array}{c}\text { Depth } \\
(\mathbf{m})\end{array}$ & $\begin{array}{c}\mathrm{K} \\
(\%)\end{array}$ & $\begin{array}{c}\text { Th } \\
(\mathbf{p p m})\end{array}$ & $\begin{array}{c}\mathrm{U} \\
(\mathbf{p p m})\end{array}$ & $\begin{array}{c}\text { Total dose rate } \\
(\mathbf{G y} / \mathbf{k a})\end{array}$ \\
\hline EVA1018 & $0.72 \pm 0.02$ & $1.45 \pm 0.07$ & $9.9 \pm 0.5$ & $3.19 \pm 0.16$ & $2.89 \pm 0.28$ \\
\hline EVA1019 & $1.75 \pm 0.02$ & $1.46 \pm 0.07$ & $9.7 \pm 0.5$ & $2.78 \pm 0.14$ & $2.86 \pm 0.27$ \\
\hline EVA1020 & $2.83 \pm 0.02$ & $1.62 \pm 0.08$ & $11.3 \pm 0.6$ & $3.12 \pm 0.16$ & $3.19 \pm 0.31$ \\
\hline EVA1021 & $2.73 \pm 0.02$ & $1.47 \pm 0.07$ & $10.5 \pm 0.5$ & $3.02 \pm 0.15$ & $3.08 \pm 0.30$ \\
\hline EVA1022 & $3.70 \pm 0.02$ & $1.65 \pm 0.08$ & $10.2 \pm 0.5$ & $3.60 \pm 0.18$ & $3.04 \pm 0.30$ \\
\hline EVA1023 & $4.58 \pm 0.02$ & $1.70 \pm 0.09$ & $11.6 \pm 0.6$ & $3.57 \pm 0.18$ & $3.32 \pm 0.33$ \\
\hline EVA1024 & $5.42 \pm 0.02$ & $1.78 \pm 0.09$ & $11.1 \pm 0.6$ & $3.46 \pm 0.17$ & $3.54 \pm 0.35$ \\
\hline EVA1025 & $6.92 \pm 0.02$ & $1.75 \pm 0.09$ & $11.8 \pm 0.6$ & $3.33 \pm 0.17$ & $3.50 \pm 0.36$ \\
\hline EVA1026 & $7.71 \pm 0.02$ & $1.85 \pm 0.09$ & $12.9 \pm 0.7$ & $3.61 \pm 0.18$ & $3.96 \pm 0.39$ \\
\hline EVA1091 & $9.5 \pm 0.1$ & $1.91 \pm 0.10$ & $20.0 \pm 1.0$ & $2.10 \pm 0.11$ & $4.77 \pm 0.37$ \\
\hline EVA1089 & $9.5 \pm 0.1$ & $1.85 \pm 0.07$ & $19.1 \pm 1.0$ & $2.10 \pm 0.11$ & $4.12 \pm 0.35$ \\
\hline EVA1028 & $9.6 \pm 0.1$ & $1.98 \pm 0.10$ & $13.6 \pm 0.7$ & $2.10 \pm 0.11$ & $4.31 \pm 0.33$ \\
\hline EVA1029 & $10.2 \pm 0.1$ & $2.00 \pm 0.10$ & $13.5 \pm 0.7$ & $3.66 \pm 0.18$ & $4.70 \pm 0.38$ \\
\hline EVA1090 & $9.5 \pm 0.1$ & $1.91 \pm 0.10$ & $14.8 \pm 0.7$ & $2.10 \pm 0.11$ & $4.08 \pm 0.31$ \\
\hline
\end{tabular}

Table 3. Radionuclide concentrations for luminescence samples surrounding the $\mathrm{Cl}$ tephra layer at Urluia loess locality, near Rasova-Valea cu Pietre site, southeastern Romania (Fitzsimmons et al. 2013; Fitzsimmons and Hambach, in press). 
a)

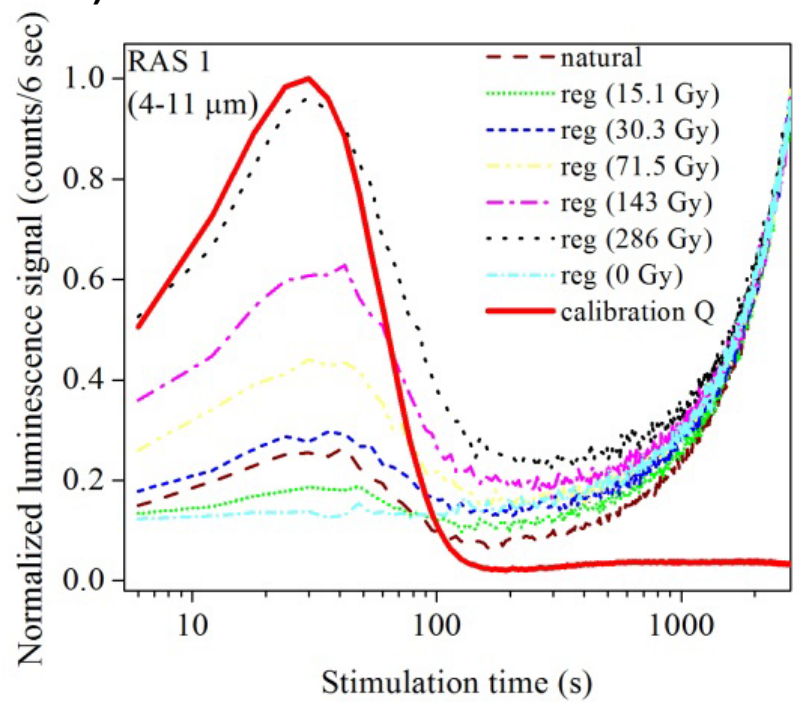

b)

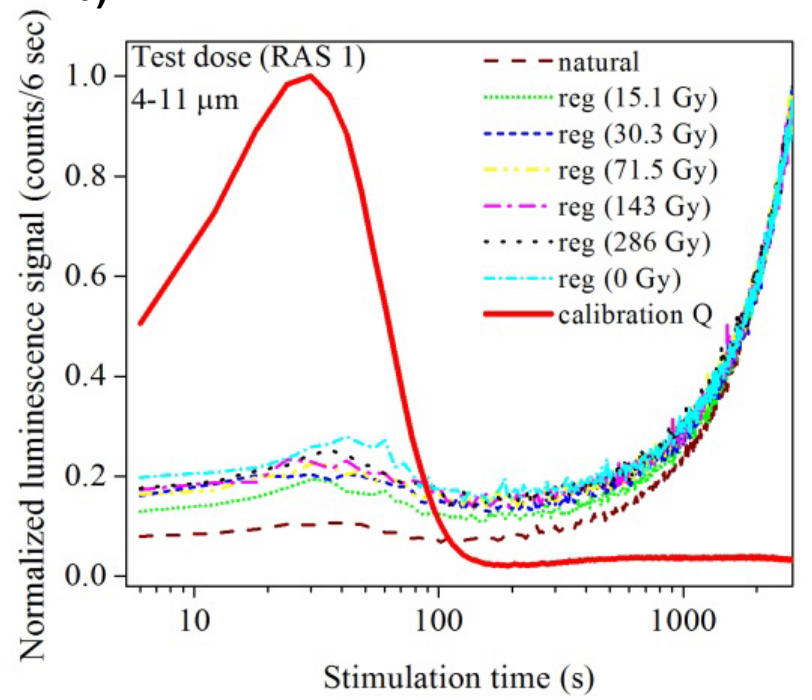

Fig. 8. a) $L M-O S L$ of natural and regenerated signals of fine (4-11 $\mu \mathrm{m})$ quartz extracted from sample RAS 1 in comparison to calibration quartz. b) Same data for the corresponding test dose signals. One data channel represents $6 s$ of stimulation. For a better visual comparison, each curve was normalized to its maximum value.

\section{Single grain measurement}

\section{$D_{e}$ measurement conditions}

Single grain equivalent dose $\left(D_{\mathrm{e}}\right)$ measurements were undertaken for the 125-180 $\mu \mathrm{m}$ quartz fraction of the samples RAS 2 and RAS 4 using an automated Risø TLDA-20 reader in the Luminescence Dating Laboratory of the Max Planck Institute for Evolutionary Anthropology in Leipzig. The reader is equipped with a single grain attachment and green laser emitting at $532 \mathrm{~nm}$, for light stimulation of single grains. Irradiation was provided by calibrated ${ }^{90} \mathrm{Sr} /{ }^{90} \mathrm{Y}$ beta sources (Bøtter-Jensen et al., 2000). Luminescence signal detection was performed under the same conditions as for the single aliquot measurements. Quartz extraction followed the conventional procedures for luminescence sample preparation described in Samples and analytical facilities section. The number of discs was determined by the amount of sand-sized material extracted; for RAS 2, three discs (300 grains) were measured, while six discs (600 grains) were measured for RAS 4. Single grains were loaded by sweeping grains over the 100 individual holes of single grain discs with a small brush. Since the grains represent fine-grained sand $(125-180 \mu \mathrm{m})$ and the size of the disc holes is somewhat larger, the discs were checked under an optical microscope with filtered red illumination to ensure that only one grain occupied each hole.

The $D_{\mathrm{e}}$ was measured using the single-aliquot regenerative-dose (SAR) protocol of Murray and Wintle (2000; 2003). For consistency between the single aliquot and single grain measurements, preheat and cut-heat temperatures of $220^{\circ} \mathrm{C}$ and $180^{\circ} \mathrm{C}$ respectively were used for the single grain analyses. The OSL signal was measured as the integral of the first $1 \mathrm{~s}$, with an early background subtraction determined by the integral of the subsequent $2 \mathrm{~s}$ to reduce the possibility of signal contamination by non-fast components, and by any feldspars which may have remained after processing (Cunningham and Wallinga, 2010). Since the number of grains available for analysis was limited, an extended recycling test similar in form to a dose recovery test was included at the end of each protocol in order to assess the characteristics of each grain. Although this test cannot replace a full dose recovery test on unaltered grains (sensu Murray and Wintle, 2003), due to likely sensitivity changes experienced as a result of heating and irradiation (Wintle and Murray, 1999; 2000), it was hoped that further characterisation of the intrinsic luminescence properties of the quartz could be made by this additional test, given the small quantities of grains available for analysis. These "extended recycling/substitute dose recovery" tests were undertaken only for those grains which passed the selection criteria as discussed below.

Since not all grains yield useful OSL signals for dating (Jacobs and Roberts, 2007), individual grains were analysed for their suitability using a set of selection criteria based on fundamental characteristics. These criteria were defined as grains which emit an OSL signal greater than three times the background level; produce a doseresponse curve which can be fitted to a simple exponential or exponential-plus-linear function (as observed previously in Romanian loess quartz); result in sensitivitycorrected recycling values within $25 \%$ of unity and yield IR depletion ratios within $20 \%$ of unity. The threshold for recycling and IR depletion ratios is somewhat higher than in previous studies (e.g. Duller, 2003) due to the inherently low sensitivity of these loess samples, which results in large uncertainties. 


\section{Luminescence sensitivity}

The number of luminescent grains identified by single grain analyses for samples RAS 2 and RAS 4 totalled 45 and 85 grains respectively (see Table 4 ). This corresponds to $15 \%$ and $14 \%$ of the total measured grains. This proportion is consistent with observations from other single grain studies from a range of contexts, from aeolian to fluvial and cave deposits (Jacobs et al., 2006; Fitzsimmons, 2011). However, the majority of sand-sized grains measured from Valea cu Pietre were categorised as dim (yielding $<20$ counts in the initial channel of the natural signal). Aeolian sediments in general have been thought to yield relatively high sensitivities (Fitzsimmons et al., 2010; Fitzsimmons, 2011; Li and Wintle, 1992), as have sediments which have undergone long-distance transport within rivers (Pietsch et al., 2008). Therefore the Romanian loess-forming, sand-sized grains, which are not only assumed to be aeolian but have undergone longdistance fluvial transport (Smalley and Leach, 1978), may reasonably have been assumed to exhibit a high efficiency of charge transfer between traps and luminescence centres. However, loess of glacial origin, transported within a fluvial system involving a high proportion of suspended load (the Danube), may also have prevented substantial light infiltration and therefore extensive bleaching of the luminescence signal to those fluvial sediments during transport, may have sustained low sensitivities in the quartz (e.g. Preusser et al., 2006). Conversely, it is also possible that the different size fractions measured in this study - fine $(4-11 \mu \mathrm{m})$, medium (63-

Table 4. Summary of initial assessments of luminescent grains for samples RAS 2 and RAS 4. Signal brightness is assessed using a scale based on initial counts. Dose response curves were assessed based on whether they yielded an unambiguous increase in signal with administered dose, and could be fitted using a single exponential or exponential + linear function. Those grains not fitting these criteria did not pass. The recycling and IR depletion cut-offs of $25 \%$ and $20 \%$ departure from unity include grains for which the error range also lies within those cut-offs, in order to facilitate further analyses.

\begin{tabular}{lcc}
\hline Sample & RAS 2 & RAS 4 \\
\hline Number of discs (grains) analysed & $3(300)$ & $6(600)$ \\
\hline Luminescence signal & & \\
\hline Grains yielding clearly decaying signal & 45 & 85 \\
\hline Dim grains (<20 counts) & 23 & 48 \\
\hline Dim-moderate (21-60 counts) & 9 & 20 \\
\hline Medium-bright (61-150 counts) & 7 & 11 \\
\hline Bright (>151 counts) & 6 & 6 \\
\hline Of bright grains, "supergrains" (>1000 counts) & 1 & 2 \\
\hline Dose response & & \\
\hline Consistently increasing response with dose & 11 & 22 \\
\hline Exponential fit & 9 & 20 \\
\hline Exponential + linear fit & 2 & 2 \\
\hline Recycling $\pm 25 \%$ of unity & 14 & 25 \\
\hline IR depletion ration $\pm 20 \%$ of unity & 12 & 18 \\
\hline Dose recovery $\pm 25 \%$ of unity & 3 & 0 \\
\hline Grains passing criteria for analysis & 3 & 0 \\
\hline
\end{tabular}

$90 \mu \mathrm{m})$ and sand-sized $(125-180 \mu \mathrm{m})$ - are derived from different sources, experienced different sedimentation histories, and consequently developed different luminescence properties, of which only the characteristics of sand-sized grains can be investigated at individual grain level. Source rock lithology has been proposed to influence luminescence sensitivity (Li et al., 2007; Westaway, 2009). Given that sand-sized material is generally not present in Danubian loess (e.g. Marković et al., 2004), it is entirely possible that the sand-sized grains isolated at Valea cu Pietre originated from local protoliths and therefore inherited different luminescence characteristics to the finer grains, which are derived from glacial grinding and long-distance fluvial transport from much further upstream. Irrespective of these considerations, low luminescence sensitivity results in very high uncertainties in both the natural and regenerated dose signals, which is particularly problematic when measuring single grains. Consequently, these dim grains cannot be used to reconstruct dose response, and therefore to determine age.

\section{$D_{e}$ measurement results}

Sand-sized grains yielding initial natural signals exceeding 20 counts in the first channel $(0.2 \mathrm{~s}$; "sufficiently bright grains") constituted $7 \%$ and $6 \%$ of the RAS 2 and RAS 4 samples respectively (Table 4). Fig. 9 shows the luminescence characteristics of a single sufficiently bright grain from sample RAS 2. This sample exhibits a moderately dim signal and simple exponential dose response, and is one of the better-behaved grains analysed from the suite of grains from both samples.

The sufficiently luminescent grains were then assessed for their behaviour according to the internal checks of the SAR protocol (Murray and Wintle, 2000; 2003). Table 5 provides a summary of the initial assessments of those luminescent grains. The results indicate that the presence of sufficiently bright luminescence signals provides no guarantee of satisfactory performance using the SAR protocol. Only half (3.5\%) of these sufficiently bright grains yielded dose response curves which increased with regenerative dose and could be fitted to a simple exponential or exponential-plus-linear function. A similar proportion yielded recycling and IR depletion ratios within $25 \%$ and $20 \%$ of unity, respectively, despite the relatively high thresholds for acceptance adopted in this study. This proportion is at the lower range of typical single grain analyses for sediments from a range of contexts (e.g. Jacobs et al., 2006), but drops substantially when the results of extended recycling (substitute dose recovery tests) are taken into account.

In this study, the extended recycling test was included at the end of the main SAR protocol for each individual grain, following double-bleaching of each grain using the green single grain laser, and administration of a dose of approximately $200 \mathrm{~Gy}$ (believed to be comparable to the dose accumulated during burial). Only the resulting extended recycling ratios of those grains which passed SAR 

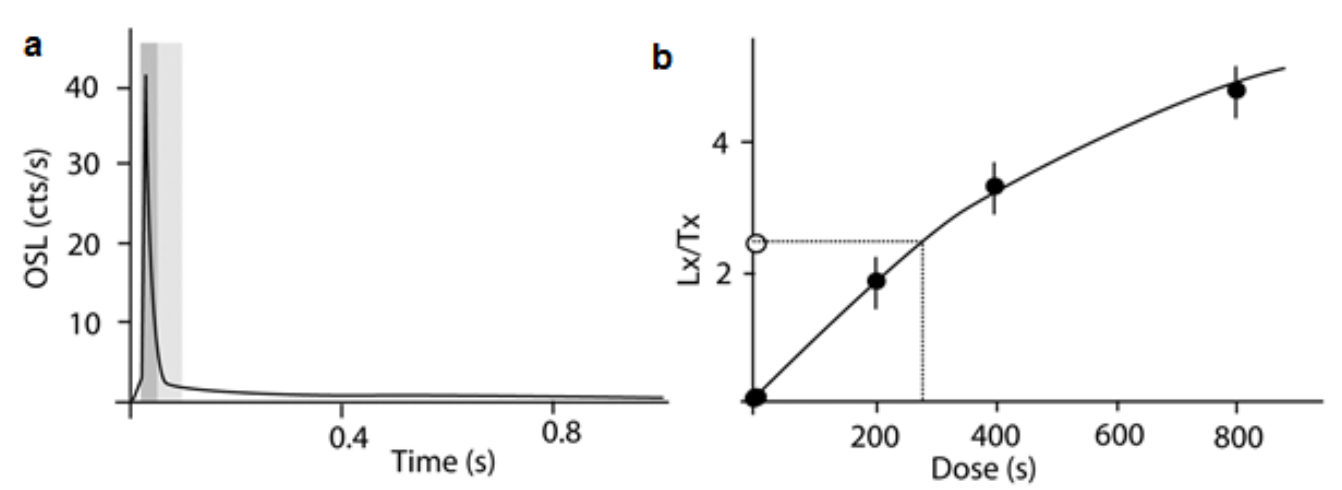

Fig. 9. OSL characteristics of 125-180 $\mu$ m quartz from Valea cu Pietre sample RAS 2 (disc 9, grain 64). a) Rapidly decaying OSL signal indicating dominance of the fast component; the channels used for integration of the OSL signal and for background subtraction are shown in dark and light grey, respectively. b) Dose response curve, showing test-dose-corrected natural signal, for the same grain.

Table 5. Luminescence characteristics for those single grains from samples RAS 2 and RAS 4 which passed initial selection criteria. The final assessment regarding analysis for age calculation, determined by equivalent dose error, recycling, IR depletion ratios, and dose recovery tests, is also listed. The grains accepted for final age calculation are highlighted by italics. $Y=Y e s ; N=$ No.

\begin{tabular}{|c|c|c|c|c|c|c|c|}
\hline Disc & Grain & $D_{\mathrm{e}}(\mathrm{Gy})$ & $\begin{array}{c}\text { Recycling } \\
\text { ratio }\end{array}$ & Dose response fit & $\begin{array}{c}\text { IR depletion } \\
\text { ratio }\end{array}$ & $\begin{array}{c}\text { Dose recovery } \\
\text { ratio }\end{array}$ & $\begin{array}{l}\text { Accept for age } \\
\text { calculation }\end{array}$ \\
\hline \multicolumn{8}{|l|}{ RAS 2} \\
\hline 9 & 32 & $177 \pm 29$ & $1.71 \pm 0.44$ & Exp+lin & $0.73 \pm 0.18$ & 1.04 & $Y$ \\
\hline 9 & 43 & $142 \pm 46$ & $1.12 \pm 0.48$ & $\operatorname{Exp}$ & $0.91 \pm 0.41$ & No fit & $\mathrm{N}$ \\
\hline 9 & 49 & $57.7 \pm 20$ & $0.86 \pm 0.37$ & Exp & $0.85 \pm 0.32$ & 0.81 & $Y$ \\
\hline 9 & 64 & $71.6 \pm 25.2$ & $0.83 \pm 0.33$ & Exp & $0.64 \pm 0.27$ & 0.96 & $Y$ \\
\hline 9 & 78 & $106 \pm 24$ & $1.25 \pm 0.32$ & Exp & $0.88 \pm 0.23$ & 0.22 & $\mathrm{~N}$ \\
\hline 13 & 59 & $174 \pm 50$ & $1.06 \pm 0.26$ & Exp & $1.43 \pm 0.36$ & 1.72 & $\mathrm{~N}$ \\
\hline 13 & 71 & $249 \pm 302$ & $1.04 \pm 0.30$ & Exp+lin & $1.02 \pm 0.29$ & 0.44 & $\mathrm{~N}$ \\
\hline 13 & 75 & $54.2 \pm 20.7$ & $1.76 \pm 1.06$ & Exp & $0.72 \pm 0.46$ & No fit & $\mathrm{N}$ \\
\hline 13 & 86 & $172 \pm 38$ & $1.32 \pm 0.24$ & Exp & $1.02 \pm 0.19$ & 1.29 & $\mathrm{~N}$ \\
\hline 15 & 69 & $248 \pm 83$ & $1.03 \pm 0.28$ & Exp+lin & $0.87 \pm 0.23$ & 0.43 & $\mathrm{~N}$ \\
\hline 15 & 78 & $61.4 \pm 14.8$ & $1.15 \pm 0.22$ & Exp & $1.05 \pm 0.21$ & 1.35 & $\mathrm{~N}$ \\
\hline \multicolumn{8}{|l|}{ RAS 4} \\
\hline 3 & 39 & $340 \pm 76$ & $0.92 \pm 0.21$ & Exp & $1.51 \pm 0.34$ & Saturated & $\mathrm{N}$ \\
\hline 5 & 49 & $215 \pm 205$ & $0.91 \pm 0.13$ & Exp+lin & $0.86 \pm 0.12$ & 0.49 & $\mathrm{~N}$ \\
\hline 7 & 37 & $313 \pm 256$ & $0.86 \pm 0.55$ & Exp & $1.09 \pm 0.67$ & 1.40 & $\mathrm{~N}$ \\
\hline 7 & 90 & $549 \pm 42$ & $1.06 \pm 0.06$ & Exp+lin & $0.91 \pm 0.05$ & Saturated (supergrain) & $\mathrm{N}$ \\
\hline 9 & 34 & $876 \pm 447$ & $0.78 \pm 0.26$ & Exp & $1.19 \pm 0.39$ & No fit & $\mathrm{N}$ \\
\hline 9 & 96 & $552 \pm 163$ & $2.34 \pm 1.12$ & Exp & $1.09 \pm 0.57$ & 0.25 & $\mathrm{~N}$ \\
\hline 13 & 34 & $86.1 \pm 16.4$ & $1.11 \pm 0.13$ & Exp & $0.78 \pm 0.10$ & 0.70 & $\mathrm{~N}$ \\
\hline 13 & 50 & $597 \pm 190$ & $1.38 \pm 0.28$ & Exp & $0.76 \pm 0.13$ & 0.58 & $\mathrm{~N}$ \\
\hline 13 & 71 & $181 \pm 62$ & $0.99 \pm 0.49$ & Exp & $1.06 \pm 0.49$ & Saturated & $\mathrm{N}$ \\
\hline 13 & 90 & $396 \pm 185$ & $0.73 \pm 0.22$ & Exp & $0.83 \pm 0.25$ & 0.31 & $\mathrm{~N}$ \\
\hline
\end{tabular}

selection criteria were analysed, in order to ensure the strictest quality control for dating. The extended recycling tests cannot fully replace dose recovery tests on previously unmeasured grains (sensu Murray and Wintle, 2003), however in the case of very low single grain yield such as for the Valea cu Pietre samples, the findings provide valuable information on the intrinsic properties of these grains. The results indicate surprising inconsistency between grains accepted for equivalent dose analyses, i.e. passing basic SAR-protocol checks, and those passing the extended recycling test. Of the analyses, only three grains from RAS 2 ( $1 \%$ of the total number of grains analysed) and none from RAS $4(0 \%)$ passed the extended recycling test, which was assessed in the same way as a dose recovery test. Three of the RAS 4 grains yielded an extended recycling signal which was saturated with respect to dose, despite providing much larger equivalent dose estimates. This inconsistent luminescence behaviour strongly indicates that these samples are unsuitable for dating, despite passing internal SAR protocols. It also highlights 
the utility of undertaking these sorts of tests for individual grains as part of the measurement protocol. Perhaps most significantly, however, the inconsistency between grains passing basic SAR-protocol checks and the extended recycling test suggests that there remain characteristics of the inherent properties of individual grains that have not previously been identified.

Table 5 summarises the results of those grains which passed internal SAR checks, combined with the dose recovery ratios and corresponding assessment as to whether each grain is acceptable for age calculation. The number of accepted grains from the sample set analysed in this study -3 for RAS 2 and 0 for RAS 4 - is clearly insufficient for statistically robust determination of the age, proposed to be at least 50 grains (Rodnight, 2008). The accepted grains for RAS 2 range between approximately 58-180 Gy, and clearly do not correspond to a single age. The single grain investigations yield insufficient grains passing selection criteria to adequately determine age or to directly compare with the finer-grained measurements.

\section{DISCUSSIONS AND CONCLUSIONS}

The ${ }^{40} \mathrm{Ar} /{ }^{39} \mathrm{Ar}$ composite age of $39.28 \pm 0.11 \mathrm{ka}$ obtained from proximal pyroclastic deposits in the Campi Flegrei Volcanic Field (De Vivo et al., 2001) is widely considered to be the most reliable age of the CI eruption. This age is consistent, within error, with the initial constraint on the depositional age of the Y-5 tephra to $38 \pm 2.5 \mathrm{ka}$ based on marine core oxygen-isotope stratigraphy (Thunnel et al., 1978), as well as with the ${ }^{40} \mathrm{Ar} /{ }^{39} \mathrm{Ar}$ age of $41.1 \pm 2.1 \mathrm{ka}$ on marine CI tephra material from the Tyrrhenian Sea (Ton-That et al., 2001).

Luminescence investigations carried out on an archaeological profile from Kostenki-Borshchevo in Russia yielded OSL ages ranging between $52.4 \pm 3.8 \mathrm{ka}$ and $45.2 \pm 3.2 \mathrm{ka}$ for samples below the CI ash layer, and younger than $30.3 \pm 2.21 \mathrm{ka}$ on samples collected above the ash layer. Moreover, OSL ages of $47.7 \pm 3.4$ and $32.2 \pm 2.3 \mathrm{ka}$, respectively, were obtained for samples bracketing the same ash layer in another profile at Kostenki-Borshchevo (Anikovich et al., 2007). More recent luminescence investigations on Romanian loess sections containing the $\mathrm{CI}$ ash layer also provide strong support for our luminescence results. At the site of Caciulatesti in the Jiu valley, quartz OSL dating of four different grain sizes yields average ages of $40.4 \pm 1.3 \mathrm{ka}$ and $40.7 \pm 1.2 \mathrm{ka}$ for the sediment below and above the level of the ash layer, respectively (Constantin et al., 2012). Apart from Caciulatesti, luminescence investigations of the CI tephra layer at Lunca in the Olt valley yielded an age of $40.3 \pm 3.5 \mathrm{ka}$ (Veres et al., 2013). The nearby exceptionally thick $\mathrm{CI}$ occurrence at Urluia quarry was constrained to between $48.8 \pm 3.9 \mathrm{ka}, 41.1 \pm 3.4 \mathrm{ka}$ and $38.7 \pm 3.3 \mathrm{ka}$ on samples below, and $36.2 \pm 3.5 \mathrm{ka}$ on one sample above the ash layer (Fitzsimmons et al., 2013).
Considering the age of the CI eruption and of its distally deposited ash, the luminescence ages obtained in this study on fine quartz grains $(4-11 \mu \mathrm{m})$ confirm the expected depositional age of the CI tephra layer identified at Rasova-Valea $\mathrm{Cu}$ Pietre.

The SAR-OSL age obtained for the medium (63-90 $\mu \mathrm{m})$ fraction of sample RAS 4 appears to overestimate the age of the CI tephra layer. The difference between the medium and fine-grained quartz ages can be correlated to the size-related age offsets previously reported for loess deposits in south-eastern Romania (Timar-Gabor et al., 2011; Constantin et al., in press). It is also interesting to note that the discrepancy in different grain-size ages observed in the case of sample RAS 4 is in contrast to the consistency between ages obtained for RAS 1. These findings raise concern not only for the luminescence properties of the quartz from the investigated samples, but also for the reliability of the SAR protocol in this particular case. Overall, the reported ages confirm the correlation established based on glass chemical fingerprinting data and the previous age discrepancy reported for the loess sections from southern Romania is not observed up to the same degree, at this particular location. Most probably, this particularity is a result of the relative youth of the samples from Valea cu Pietre.

The single grain analyses, performed for the first time on loessic quartz to our knowledge, demonstrate that sand-sized Romanian loessic quartz exhibits low sensitivity at single-grain level and responds poorly to the internal checks of the SAR protocol. In particular, single grain measurements show very poor post-SAR dose recovery response, and suggest that there remain some intrinsic luminescence properties of individual grains of quartz which are poorly known and need to be more rigorously investigated. This most likely resides in a combination between geological processes, the relative immaturity of the Valea cu Pietre sediments, and consequently the luminescence characteristics inherited from the source rocks. The results do, however, provide an insight into the luminescence characteristics of Romanian loess, which has up until now not been possible due to the lack of sand-sized grains within previously investigated loess sequences. The proximity of the Valea cu Pietre site to the Danube River, however, most likely facilitated the accumulation of a small proportion of coarser-grained material which cannot be found elsewhere in the Eastern European loess steppe (e.g. Jipa, in press), through shorter-distance aeolian transport from the small component of sandy bedload within the Danube. This situation is unusual for Danubian loess and therefore the results examined here may not be representative of the whole basin. The hypothesized origins of the sand-sized quartz stand in contrast to those of the longer-travelled silt-sized material, and may have resulted in different grain-sizes with different sedimentary histories and therefore different inherited luminescence characteristics. At present, without investigating the luminescence properties of the finer- 
grained quartz at single grain level, the prospect of two separate sediment populations with different origins cannot be confirmed. However, if this is the case, then it may well explain why the fine-grained $(4-11 \mu \mathrm{m})$ material yields better results for dating than the single, sand-sized grains.

Our observations, including the issue of the relative contributions of the fast and the slow components of the LM-OSL signals as function of magnitude of the given dose, highlight the need for further detailed investigations into the luminescence properties of different quartz grain size fractions. In addition, our results suggest the need to further investigate the origin of quartz contributions from different primary sources in the Lower Danube loess fields.

\section{ACKNOWLEDGEMENTS}

V. Anechitei-Deacu, A. Timar-Gabor and D. Veres acknowledge the financial support from a grant of the Romanian National Authority for Scientific Research CNCS-UEFISCDI, PN-II-RU-TE-2011-3-0062, nr. 73/05.10.2011. V. Anechitei-Deacu is also grateful for financial support from Babes-Bolyai University Cluj, through an internal research grant for students. K.E. Fitzsimmons wishes to thank Steffi Albert for assistance in the laboratory at MPI-EVA.

\section{REFERENCES}

Adamiec G and Aitken M, 1998. Dose-rate conversion factors: update. Ancient TL 16(2): 37-50.

Anikovich MV, Sinitsyn AA, Hoffecker JF, Holliday VT, Popov VV, Lisitsyn SN, Forman SL, Levkovskaya GM, Pospelova GA, Kuz'mina IE, Burova ND, Goldberg P, Macphail RI, Giaccio B and Praslov ND, 2007. Early Upper Paleolithic in Eastern Europe and implications for the dispersal of modern humans. Science 315: 223-315, DOI 10.1126/science.1133376.

Bailey RM, 2000. The slow component of quartz optically stimulated luminescence. Radiation Measurements 32(3): 233-246, DOI 10.1016/S1350-4487(99)00285-1.

Bellia S, Brai M, Hauser S, Puccio P and Rizzo S, 1997. Natural radioactivity in a volcanic island: Ustica, Southern Italy. Applied Radiation and Isotopes 48(2): 287-293, DOI 10.1016/S09698043(96)00150-9.

Bøtter-Jensen L, Bulur E, Duller GAT and Murray AS, 2000. Advances in luminescence instrument systems. Radiation Measurements 32(5-6): 523-528, DOI 10.1016/S1350-4487(00)00039-1.

Brai M, Hauser S, Bellia S, Puccio P and Rizzo S, 1995. Natural gradiation of rocks and soils from Vulcano (Aeolian islands, Mediterranean Sea). Nuclear Geophysics 9: 121-127.

Brai M, Basile S, Bellia S, Hauser S, Puccio P, Rizzo S, Bartolotta A and Licciardello A, 2002. Environmental radioactivity at Stromboli (Aeolian Islands). Applied Radiation and Isotopes 57(1): 99107, DOI 10.1016/S0969-8043(02)00074-X.

Civetta L, Gasparini P and Adams AS, 1970. Geochronology and geochemical trends of volcanic rocks from Campania, southern Italy. Ecolgae Geologicae Helvetie 63: 57-68.

Civetta L and Gasparini P, 1973. U and Th distributions in recent volcanics from southern Italy: magmatological and geophysical implications. Rivista Italiana di Geofisica XXII (3/4): 127-139.

Civetta L, Orsi G, Pappalardo L, Fisher RV, Heiken G and Ort M, 1997. Geochemical zoning, mingling, eruptive dynamics and depositional processes e the Campanian Ignimbrite, Campi Flegrei caldera,
Italy. Journal of Volcanology and Geothermal Research 75(3-4): 183-219, DOI 10.1016/S0377-0273(96)00027-3.

Constantin D, Timar-Gabor A, Veres D, Begy R and Cosma C, 2012. SAR-OSL dating of different grain-sized quartz from a sedimentary section in southern Romania interbedding the Campanian Ignimbrite/Y5 ash layer. Quaternary Geochronology 10: 81-86, DOI 10.1016/j.quageo.2012.01.012.

Constantin D, Begy R, Vasiliniuc S, Panaiotu C, Necula C, Codrea V and Timar-Gabor A, in press. High-resolution OSL dating of the Costinesti section (Dobrogea, SE Romania) using fine and coarse quartz. Quaternary International, DOI 10.1016/j.quaint.2013.06.016.

Cunningham AC and Wallinga J, 2010. Selection of integration timeintervals for quartz OSL decay curves. Quaternary Geochronology 5(6): 657-666, DOI 10.1016/j.quageo.2010.08.004.

De Vivo B, Rolandi G, Gans PB, Calvert A, Bohrson WA, Spera FJ and Belkin HE, 2001. New constraints on the pyroclastic eruptive history of the Campanian volcanic plain (Italy). Mineralogy and Petrology, 73(1-3): 47-65, DOI 10.1007/s007100170010.

Duller GAT, 2003. Distinguishing quartz and feldspar in single grain luminescence measurements. Radiation Measurements 37(2): 161165, DOI 10.1016/S1350-4487(02)00170-1.

Fedele FG, Giaccio B, Isaia R and Orsi G, 2003. The Campanian Ignimbrite Eruption, Heinrich Event 4, and Palaeolithic Change in Europe: a High- Resolution Investigation. Geophysical Monograph Volcanism and the Earth's Atmosphere. American Geophysical Union 139: 301-325, DOI 10.1029/139GM20.

Fitzsimmons KE, 2011. An Assessment of the luminescence sensitivity of Australian quartz with respect to sediment history. Geochronometria 38(3): 199-208, DOI 10.2478/s13386-011-0030-9.

Fitzsimmons KE, Rhodes EJ and Barrows TT, 2010. OSL dating of southeast Australian quartz: A preliminary assessment of luminescence characteristics and behavior. Quaternary Geochronology 5(2-3): 91-95, DOI 10.1016/j.quageo.2009.02.009.

Fitzsimmons KE and Hambach U, in press. Loess accumulation during the last glacial maximum: Evidence from Urluia, southeastern Romania. Quaternary International, DOI 10.1016/j.quaint.2013.08.005.

Fitzsimmons KE, Hambach U, Veres D and Iovita R, 2013. The Campanian Ignimbrite eruption: new data on volcanic ash dispersal and its potential impact on human evolution. PLOS ONE 8(6): e65839, DOI 10.1371/journal.pone.0065839.

Frechen M, Schweitzer U and Zander A, 1996. Improvements in sample preparation for the fine grain technique. Ancient TL 14: 15-17.

Hippolyte JC, 2002. Geodynamics of Dobrogea (Romania): new constraints on the evolution of the Tornquist-Teisseyre Line, the Black Sea and the Carpathians. Tectonophysics 357(1-4): 33-53, DOI 10.1016/S0040-1951(02)00361-X

Jacobs Z, Duller GAT and Wintle AG, 2006. Interpretation of single grain De distributions and calculation of De. Radiation Measurements 41(3): 264-277, DOI 10.1016/j.radmeas.2005.07.027.

Jacobs Z and RG Roberts, 2007. Advances in optically stimulated luminescence dating of individual grains of quartz from archeological deposits. Evolutionary Anthropology: Issues, News, and Reviews 16(6): 210-223, DOI 10.1002/evan.20150.

Jipa DC, in press. The Conceptual Sedimentary Model of the Lower Danube Loess Basin: Sedimentogenetic Implications. Quaternary International, DOI 10.1016/j.quaint.2013.06.008.

Lang A, Lindauer S, Kuhn R and Wagner GA, 1996. Procedures used for optically and infrared stimulated luminescence dating of sediments in Heidelberg. Ancient TL 14(3): 7-11.

Li S-H and Wintle AG, 1992. Luminescence sensitivity change due to bleaching of sediments. International Journal of Radiation Applications and Instrumentation. Part D. Nuclear Tracks and Radiation Measurements 20(4): 567-573, DOI 10.1016/13590189(92)90006-H.

Li S-H, Chen YY, Li B, Sun JM and Yang LR, 2007. OSL dating of sediments from deserts in northern China. Quaternary Geochronology 2(1-4): 23-28, DOI 10.1016/j.quageo.2006.05.034.

Lowe J, Barton N, Blockley S, Ramsey CB, Cullen VL, Davies W, Gamble C, Grant K, Hardiman M, Housley R, Lane CS, Lee S, 
Lewis M, MacLeod A, Menzies M, Müller W, Pollard M, Price C, Roberts AP, Rohling EJ, Satow C, Smith VC, Stringer CB, Tomlinson EL, White D, Albert P, Arienzo I, Barker G, Borić D, Carandente A, Civetta L, Ferrier C, Guadelli J-L, Karkanas P, Koumouzelis M, Müller UC, Orsi G, Pross J, Rosi M ShalamanovKorobar L, Sirakov N and Tzedakis PC, 2012. Volcanic ash layers illuminate the resilience of Neanderthals and early modern humans to natural hazards. Proceedings of the National Academy of Sciences of the United States of America 109(34): 13532-13537, DOI 10.1073/pnas.1204579109.

Marković SB, Kostić NS, Oches EA, 2004. Paleosols in the Ruma loess section (Vojvodina, Serbia). Revista Mexicana de Ciencias Geologicas 21: 79-87.

Mejdahl V, 1979. Thermoluminescence dating: beta-dose attenuation in quartz grains. Archaeometry 21(1): 61-72, DOI 10.1111/j.14754754.1979.tb00241.x.

Munteanu MT, Munteanu E, Stiuca E, Macaleti R and Dumitrascu G, 2008. Some aspects concerning the Quaternary deposits in south Dobrogea. Acta Palaeontologica Romaniae 6: 229-236.

Murray AS and Wintle AG, 2000. Luminescence dating of quartz using an improved single-aliquot regenerative-dose protocol. Radiation Measurements 32(1): 57-73, DOI 10.1016/S1350-4487(99)00253$\mathrm{X}$.

Murray AS and Wintle AG, 2003. The single aliquot regenerative dose protocol: potential for improvements in reliability. Radiation Measurements 37(4-5): 377-381, DOI 10.1016/S13504487(03)00053-2.

Pietsch TJ, Olley JM and Nanson GC, 2008. Fluvial transport as a natural luminescence sensitiser of quartz. Quaternary Geochronology 3(4): 365-376, DOI 10.1016/j.quageo.2007.12.005.

Pop G, Andreescu I, Avram E, Draganescu A, Ghenea C, Ghenea A and Mihailescu N, 1991. Harta geologicăa României scara 1:50.000, Foaia Aliman (Geological map of Romania at scale 1: 50 000, Aliman Section). Institutul Geologic al Romaniei, Bucuresti.

Prescott JR and Hutton JT, 1994. Cosmic ray contributions to dose rates for luminescence and ESR dating: Large depths and long term variations. Radiation Measurements 23(2-3): 497-500, DOI 10.1016/1350-4487(94)90086-8.

Preusser F, Chithambo ML, Götte, Martini M, Ramseyer K, Sendezera EJ, Susino GJ and Wintle AG, 2009. Quartz as a natural luminescence dosimeter. Earth-Science Reviews 97(1-4): 184-214, DOI 10.1016/j.earscirev.2009.09.006.

Preusser F, Ramseyer K and Schlüchter C, 2006. Characterisation of low OSL intensity quartz from the New Zealand Alps. Radiation Measurements $\quad 41(7-8)$ : 10.1016/j.radmeas.2006.04.019.

Pyle DM, Ricketts GD, Margari V, van Andel TH, Sinitsyn AA, Praslov ND and Lisitsyn S, 2006. Wide dispersal and deposition of distal tephra during the Pleistocene 'Campanian Ignimbrite/Y5' eruption, Italy. Quaternary Science Reviews 25(21-22): 2713-2728, DOI 10.1016/j.quascirev.2006.06.008.

Rodnight H, 2008. How many equivalent dose values are needed to obtain a reproducible distribution? Ancient TL 26(1): 3-10.

Signorelli S, Vaggelli G, Francalanci L and Rosi M, 1999. Origin of magmas feeding the Plinian phase of the Campanian Ignimbrite eruption, Phlegrean Fields (Italy): constraints based on matrixglass and glass-inclusion compositions. Journal of Volcanology and Geothermal Research 91(2-4): 199-220, DOI 10.1016/S03770273(99)00036-0.

Smalley IJ and Leach JA, 1978. The origin and distribution of the loess in the Danube basin and associated regions of East-Central Eu- rope - A review. Sedimentary Geology 21(1): 1-26, DOI 10.1016/0037-0738(78)90031-3.

Thomsen KJ, Bøtter-Jensen L, Denby P, Moska P and Murray AS, 2006. Developments in luminescence measurements techniques. Radiation Measurements 41(7-8): 768-773, DOI 10.1016/j.radmeas.2006.06.010.

Thunnel R, Federman A, Sparks S and Williams D, 1978. The origin and volcanological significance of the Y-5 ash layer in the Mediterranean. Quaternary Research 12(2): 241-253, DOI 10.1016/0033-5894(79)90060-7.

Timar A, Vandenberghe D, Panaiotu EC, Panaiotu CG, Necula C, Cosma C and Van den haute P, 2010. Optical dating of Romanian loess using fine-grained quartz. Quaternary Geochronology 5(23): 143-148, DOI 10.1016/j.quageo.2009.03.003.

Timar-Gabor A, Vandenberghe DAG, Vasiliniuc S, Panaoitu CE, Panaiotu CG, Dimofte D and Cosma C, 2011. Optical dating of Romanian loess a comparison between silt-sized and sand-sized quartz. Quaternary International 240(1-2): 62-70, DOI 10.1016/j.quaint.2010.10.007.

Timar-Gabor A, Vasiliniuc S, Vandenberghe DAG, Cosma C and Wintle AG, 2012. Investigations into the reliability of SAR-OSL equivalent doses obtained for quartz samples displaying dose response curves with more than one component. Radiation Measurements $\quad 47(9): \quad 740-745, \quad$ DOI 10.1016/j.radmeas.2011.12.001.

Timar-Gabor A and Wintle AG, 2013. On natural and laboratory generated dose response curves for quartz of different grain sizes from Romanian loess. Quaternary Geochronology 18: 34-40, DOI 10.1016/j.quageo.2013.08.001

Ton-That T, Singer B and Paterne M, 2001. ${ }^{40} \mathrm{Ar}^{139} \mathrm{Ar}$ dating of latest Pleistocene (41 ka) marine tephra in the Mediterranean Sea: implications for global climate records. Earth and Planetary Science Letters 184(3-4): 645-658, DOI 10.1016/S0012-821X(00)00358-

Vandenberghe DAG, De Corte F, Buylaert J-P, Kučera J and Van den haute $\mathrm{P}, 2008$. On the internal radioactivity in quartz. Radiation Measurements $\quad 43(2-6): \quad 771-775, \quad$ DOI 10.1016/j.radmeas.2008.01.016

Vasiliniuc S, Timar-Gabor A, Vandenberghe DAG, Panaiotu CG, Begy RCs and Cosma C, 2011. A high resolution optical dating study of the Mostiştea loess-palaeosol sequence (SE Romania) using sandsized quartz. Geochronometria 38(1): 34-41, DOI 10.2478/s13386-011-0007-8.

Veres D, Lane CS, Timar-Gabor A, Hambach U, Constantin D, Szakács A, Fülling A and Onac BP, 2013. The Campanian Ignimbrite/Y5 tephra layer - A regional stratigraphic marker for isotope Stage 3 deposits in the Lower Danube region, Romania. Quaternary International 293: 22-33, DOI 10.1016/i.quaint.2012.02.042.

Westaway KE, 2009. The red, white and blue of quartz luminescence: A comparison of De values derived for sediments from Australia and Indonesia using thermoluminescence and optically stimulated luminescence emissions. Radiation Measurements 44(5-6): 462466, DOI 10.1016/j.radmeas.2009.06.001.

Wintle AG and Murray AS, 1999. Luminescence sensitivity changes in quartz. Radiation Measurements 30(1): 107-118, DOI 10.1016/S1350-4487(98)00096-1.

Wintle AG and Murray AS, 2000. Quartz OSL: Effects of thermal treatment and their relevance to laboratory dating procedures. $R a-$ diation Measurements 32(5-6): 387-400, DOI 10.1016/S13504487(00)00057-3. 